\title{
Developing a Catalog of Socio-Sexual Behaviors of Beluga Whales (Delphinapterus leucas) in the Care of Humans
}

\author{
Heather M. Hill ${ }^{*}$, Sarah Dietrich ${ }^{2}$, Deirdre Yeater ${ }^{3}$, Mariyah McKinnon ${ }^{4}$, Malin Miller ${ }^{1}$, \\ Steve Aibel $^{5}$, and Al Dove 6
}

\author{
${ }^{1}$ St. Mary's University \\ ${ }^{2}$ University at Buffalo, State University of New York \\ ${ }^{3}$ Sacred Heart University \\ ${ }^{4}$ University of Texas at San Antonio \\ ${ }^{5}$ SeaWorld, San Antonio \\ ${ }^{6}$ Georgia Aquarium \\ *Corresponding author (Email: hhill1@ @stmarytx.edu)
}

Citation - Hill, H. M., Dietrich, S., Yeater, D., McKinnon, M., Miller, M., Aibel, S., \& Dove, A. (2015). Developing a catalog of socio-sexual behaviors of beluga whales (Delphinapterusu leucas). Animal Behavior and Cognition, 2(2), 105-123. doi: 10.12966/abc.05.01.2015

\begin{abstract}
The repertoire of socio-sexual and sexual behaviors of cetaceans is relatively unknown. The purpose of the current study was to advance the existing knowledge of socio-sexual behavior of beluga whales through the development of a behavioral catalog that lists the full repertoire of sexual and socio-sexual behaviors. A behavioral catalog was developed initially from 800 hours of observations, collected across a 7-year period from 11 belugas ranging in age (birth to $30+$ years), sex, and social groupings. Using this behavioral catalog, observations of eight additional belugas housed between two other facilities were coded for socio-sexual and sexual behaviors. Sociosexual and sexual behaviors of belugas were similar across all three facilities. Socio-sexual and sexual behaviors involved sequenced behaviors, had lateralized components, and were often subtle in nature. Some of these behaviors overlapped with potentially aggressive actions but showed distinct differences in their form, or topography. Complexity and duration of socio-sexual interactions varied depending on the age and sex of the participating belugas. The development of a complete behavioral catalog, or ethogram, of the socio-sexual and sexual behaviors has profound influences on understanding the mechanisms involved for successful reproduction, a problem that several groups of belugas in their natural habitat are currently facing.
\end{abstract}

Keywords - Beluga, Socio-sexual behavior, Sexual behavior, Behavioral repertoire, Delphinapterus leucas

Socio-sexual behavior has been studied in terms of reproductive success, copulation, and courtship. Reproductive success and copulation rates are relatively easy to identify if the definition includes documenting pregnancies, births, and intromission attempts between sexually-mature and receptive individuals. These behaviors, which are directly related to conception or involve direct stimulation of genitalia, can be defined with the term sexual (Campbell, 2007; Connor, Read, \& Wrangham, 2000; Connor, Wells, Mann, \& Read, 2000). In comparison, socio-sexual behavior includes behaviors that may not be directly involved in conception but may be used for other social purposes, such as developing and maintaining relationships between individuals or courtship (Campbell, 2007; Connor, Read, et al., 2000; Connor, Wells, et al., 2000). Courtship has traditionally been defined as the innate set of behaviors performed prior to copulation (Lorenz, 1958; Tinbergen, 1952). More recently, the definition of courtship has been expanded to include both elicited innate and emitted learned stereotyped behaviors that draw the attention of potential mates (reviewed by Freeberg, 2000). 
A review of general research on animal behavior indicated that sexual and socio-sexual interactions were the least studied area of research (27\% of articles reviewed, Hill, Artz, \& Lopez, 2014). Most studies of socio-sexual and sexual interactions have been conducted primarily with fish, amphibians, and invertebrates in laboratory settings. The sexual and socio-sexual behavior of cetaceans has not been studied as often as their biology, physiology, and genetics (representing 33\% of the sample) as compared to studies on their behavior in general (15\%), according to a review of cetacean research (Hill \& Lackups, 2010). With 16 cetacean species on the endangered species list (National Marine Fisheries, 2008), including the Cook Inlet beluga whale (Delphinapterus leucas), it is critically important to address both biological and behavioral factors that lead to reproductive success.

The lack of a cohesive and comprehensive record on the socio-sexual behavior of cetaceans demands the establishment of a behavioral repertoire of the socio-sexual behaviors including courtship and sexual behaviors including behaviors critical to copulation for three primary reasons. First, it can be surprisingly difficult to identify the socio-sexual behaviors of cetaceans. A diverse set of cetacean behaviors are suspected to have socio-sexual functions, which range from intuitively sexual behaviors to subtle, non-intuitively sexual behaviors. Without a guiding behavioral catalog or subsequent ethogram, subtle and individualized behaviors may be easily missed or misclassified when displayed. Second, distinguishing between agonistic and sexual interactions can be difficult. Researchers have recognized that biting and fighting, typically perceived as agonistic behaviors, can also be a precursor to mating (Connor, Read, et al., 2000). It is also possible that the same behaviors are displayed with subtle but important distinctions so that very similar behaviors are functionally different depending on the context. As there is currently no compiled list to guide the classification of sexual and agonistic behaviors in odontocetes, different researchers may observe the same behaviors and classify them differently.

Third, a compilation of the sexual behavioral repertoire of cetaceans can facilitate comparisons across contexts, populations (e.g., measure consistency of behaviors across controlled and wild populations), and species by moving from qualitative to quantitative measures. Observations of wild cetaceans provide access to the most naturalistic behaviors but are often constrained by visibility, making it difficult to know what behaviors may be occurring in deep waters, at a distance, or just below the surface of turbid waters (Perelberg, Veit, van der Woude, Donio, \& Shashar, 2010; Samuels \& Tyack, 2000). In contrast, observations of odontocetes in human care provide unparalleled opportunities to observe behaviors rarely visible in the wild, to analyze those behaviors for their components and sequences, to assess rates of occurrence, and to identify initiators and receivers in terms of sex, age, and reproductive status (Perelberg et al., 2010; Samuels \& Tyack, 2000). Comparisons of the behavioral repertoire across different populations of odontocetes housed in human care with their wild counterparts provide a unique opportunity to examine the ontogeny and the interaction between innate biological mechanisms, environment, social grouping, and social learning on socio-sexual behaviors. A standardized behavioral repertoire would maximize the information gained from each research context and allow more seamless cross-context comparisons and collaborations.

\section{Study of Sexual and Socio-Sexual Behaviors in Cetaceans}

Perhaps the most supported research finding on cetacean socio-sexual behavior is the frequent use of non-conceptive, sexual behavior in which direct genital stimulation occurs. Non-conceptive, sexual behavior has been observed in many cetaceans, including belugas (Glabicky, DuBrava, \& Noonan, 2010; Hill \& Ramirez, 2014), Amazon river dolphins or botos (Inia geoffrensis, Best \& da Silva, 1984), killer whales (Orcinus orca, summarized by Baird, 2000), gray whales (Eschrichtius robustus, Sauer, 1963), and bottlenose dolphins and spotted dolphins, representing the most observed species (Turisops sp., Stenella sp., respectively, Connor, Wells, et al., 2000). Nick-named "aquatic bonobos" for the similarity of their socio-sexual behaviors, many odontocetes display non-conceptive, socio-sexual interactions between immature individuals, same-sex adults, and between adult females and adult males during nonconceptive periods (Furuichi, Connor, \& Hashimoto, 2014). 
Non-conceptive, sexual behaviors appear to be relatively consistent across dolphin species. Male bottlenose dolphins initiate their first sexual interactions with their mothers as young as two days old (Mann \& Smuts, 1999). Juvenile and adult bottlenose dolphins continue to engage in frequent nonconceptive, sexual behavior, primarily between males. Females have also been observed to direct sociosexual, non-conceptive behavior towards one another, but not as frequently as males (Connor, Wells, et al., 2000). Unfortunately, the range of socio-sexual behaviors by cetaceans has not been compiled to date. Known behaviors that have been documented across a variety of species include, but are not limited to, pelvic thrusts, large groups of sexually interactive individuals (social sex ball), genital stimulation, rooster-struts, aerial displays, mouthing, S-postures, lateral presentations, and chases.

In contrast to the many observations of non-conceptive sexual behavior, copulation has been more difficult to document. Intromission between free-ranging adult dolphins has been observed only once at the Shark Bay and the Sarasota Bay populations but has been observed somewhat frequently between juveniles in wild and captive settings (Connor, Wells, et al., 2000, personal communication, K. Dudzinski). With the lack of information regarding successful intromissions and the identity of sires, a limited amount of knowledge currently exists about the conditions or behaviors necessary for successful reproduction. Previous research focused on direct male-to-male competition over mates and male coercion of females via alliance formations used to herd sexually-receptive females in some populations (Connor, Read, et al., 2000). Based on the sometimes coercive nature of cetacean mating strategies, it has been initially unclear if female choice plays a role in reproductive success (Connor, Wells, et al., 2000; Kraus \& Hatch, 2001). While coercive tactics occur, many dolphin male suitors perform a wide variety of visual displays ranging from highly elaborate to subtle forms in the presence of females (e.g., aerials and exaggerated swims, called rooster struts, and vertical S-postures, Connor \& Peterson, 1994). Although it is difficult to directly connect these behaviors to copulation, they have been compared to the coordinated displays of birds and are presumed to catch the female's attention (Connor, Read, et al., 2000). Spy hopping (Lusseau, 2006) and object carrying (Martin, da Silva, \& Rothery, 2008) have also been proposed as socio-sexual display behaviors. The frequency with which suspected courtship displays occur seems to indicate that female selection has some influence.

Research on the sexual behaviors of whales is also limited. Humpback whales (Megaptera novaengliae) and bowhead whales (Balaena mysticetus) are best known for their complex courtship songs that evolve over the season and between seasons (reviewed by Tyack, 2000). Humpback whales are also known for the competition between males for the proximity to females (Baker \& Herman, 1984; Tyack \& Whitehead, 1983). The males assert themselves as a female's primary escort based on her reproductive potential, sometimes indicated by her not presently caring for a calf (Craig, Herman, Gabriele, \& Pack, 2003). Male gray whales have been observed to turn on their sides (lateral swim), raising his pectoral fin above water, coming belly to belly with the female or male while swimming slowly (Sauer, 1963). While in this position, the males can thrust their genitals toward the females, producing a lateral S-posture (Helweg, Bauer, \& Herman, 1993). Male southern right whales (Eubalaena australis) and bowhead whales have been observed using their large pectoral fins to maneuver into belly to belly swims (Everitt \& Krogman, 1979).

\section{Belugas}

Although belugas belong to the same order and suborder as the Delphinidae family, belugas are considered a unique species (Krasnova, Bel'kovich, \& Chernetsky, 2006). Cross-species comparisons are often made to the Delphinidae family although the most fitting species for behavioral comparison has not yet been determined. Belugas travel in groups of 10 to 100 individuals across Arctic and sub-Arctic waters and summer in larger congregations in warmer waters (Brodie, 1971; Kleinenberg, Yablokov, Bel'kovich, \& Tarasevich, 1969; Sergeant, 1973). Distribution data indicate that belugas live in large social groups that appear to be organized by age and sex (Colbeck et al., 2013; O'Corry-Crowe, Suydam, Rosenberg, Frost, \& Dizon, 1997; Sergeant, 1973; Smith, Hammill, \& Martin, 1994). Adult males are 
most often grouped with other males while related adult females, younger males and females, and calves may be found in larger groups while migrating (Colbeck et al., 2013).

Although many species of cetacean have not been identified officially by the International Union for Conservation of Nature (ICUN) as threatened or endangered, some populations have failed to recover their historic population levels (e.g., the year-round belugas of Cook Inlet, National Marine Fisheries, 2008). A number of explanations currently abound, including contaminants, anthropogenic noise, vessel strikes, and insufficient breeders (potentially both males and females) (National Marine Fisheries Service, 2008). Unfortunately, while some of these factors can be measured directly, their impact on the natural behavior of the resident belugas cannot be determined currently as the understanding of beluga behavior is so elementary.

\section{Sexual and Socio-Sexual Behavior of Belugas}

Due to the difficulty of observing belugas and other cetaceans in their natural habitat, both the visual and acoustic behaviors used for socio-sexual and sexual functions are poorly understood. Studies of belugas in human care with naturalistic social groupings provide unparalleled opportunities to identify significant behaviors, to document the ontogeny of these behaviors, and to assess the influences of age, sex, social composition, and social learning on these behaviors. Yet, the socio-sexual and sexual behavior of belugas has been examined rarely. DiPaola, Akai, and Kraus (2007) developed a computerized, virtual beluga simulation of interacting and active belugas. To create this simulation program, the authors worked with aquarium researchers to develop a comprehensive description of the beluga behavioral repertoire, which included three courting and mating behaviors: presenting, posturing, and coupling (DiPaola et al., 2007). A second study focused on one sexual behavior, pelvic thrusting (Glabicky et al., 2010). Like various species of dolphins and possibly some mysticete whales, the majority of socio-sexual interactions observed for 15 belugas occurred between adult males rather than between males and females (Glabicky et al., 2010). In this study, male-to-female pelvic thrusting peaked during March while maleto-male pelvic thrusting remained stable across seasons. This pattern of behavior corroborated previous research on beluga mating seasons in the wild (Heide-Jørgensen \& Teilmann, 1994), although some seasonal variation may exist depending on the population (Bel'kovich, 1960; O'Corry-Crowe et al., 1997; Sergeant, 1973; Smith et al., 1994).

\section{Research on Populations in Human Care}

Research with animals in human care was once considered an ideal opportunity to learn about the behavior of animals that were difficult to access in their natural habitat (Samuels \& Tyack, 2000). Unfortunately, the controlled setting was de-emphasized as scientists expressed reservations about the possibility of naturalistic, spontaneous behavior (Connor \& Peterson, 1994; Perelberg et al., 2010; Samuels \& Tyack, 2000). Scientists shifted their research efforts to free-ranging animals, thereby increasing our understanding of cetacean distributions, social groupings, and behavioral states for some species. During that time, oceanarium and zoological staff expanded and increased their care for odontocetes which led to more species-appropriate social groupings (Samuels \& Tyack, 2000). Although debates still exist on the "representativeness" of behavior by odontocetes in human care (Perelberg et al., 2010), these environments $d o$ support spontaneous naturalistic behaviors, corroborated by research with free-ranging animals (e.g., Dudzinski, Gregg, Ribic, \& Kuczaj, 2009; Hill, 2009; Hill, Campbell, Dalton, \& Osborn, 2013; Krasnova et al., 2006, 2009). Studies conducted in controlled settings provide enhanced observation opportunities, facilitating a more complete documentation of a species' behavioral repertoire.

\section{The Present Study}

Three different beluga populations in human care were studied to document beluga sexual and socio-sexual behavior. The initial goal was to establish a comprehensive behavioral catalog of their sexual 
and socio-sexual behavior with agonistic behaviors sharing similar behavioral forms or topographies. The resulting catalog was used to quantify the socio-sexual and related agonistic behavioral repertoires of the three beluga populations. No hypotheses were formulated for this descriptive study.

\section{General Methodology}

For all three facilities, the data were recorded using either digital video or electronic ethogram data sheets. The video recordings were coded for continuous behavioral sequences and ethogram data were analyzed using one-minute instantaneous sampling. All data were event-sampled for socio-sexual and agonistic events. Events that were video-taped were sequenced for behavioral events and coded for initiators, receivers, and duration of interaction. Eleven belugas comprised the population of Facility A, four belugas comprised the population of Facility B, and four belugas comprised the population of Facility $\mathrm{C}$ during the data collection periods. Relevant descriptive information for each population is summarized in Table 1.

Table 1

Descriptive Information of the Populations Studied

\begin{tabular}{|c|c|c|c|c|c|c|c|}
\hline \multirow[b]{2}{*}{ Facility } & \multirow[b]{2}{*}{ Animal } & \multirow[b]{2}{*}{ Sex } & \multirow[b]{2}{*}{$\begin{array}{c}\text { Age Range } \\
\text { (years) }\end{array}$} & \multirow{2}{*}{$\begin{array}{c}\text { Age } \\
\text { Classification }\end{array}$} & \multicolumn{3}{|c|}{ Data Collection } \\
\hline & & & & & $\begin{array}{c}\text { Method } \\
\text { (V/E) }\end{array}$ & $\begin{array}{l}\text { Sampling } \\
\text { Type (C/I) }\end{array}$ & $\begin{array}{c}\text { Hours of } \\
\text { Observation }\end{array}$ \\
\hline \multirow[t]{12}{*}{$\mathrm{A}$} & & & & & $\mathrm{V} / \mathrm{E}$ & $\mathrm{C}$ & 850 \\
\hline & $\mathrm{AM}$ & Male & $20 \mathrm{~s}$ & Adult & & & \\
\hline & $\mathrm{AF}$ & Female & $20 \mathrm{~s}$ & Adult & & & \\
\hline & $\mathrm{AF}$ & Female & $20 \mathrm{~s}$ & Adult & & & \\
\hline & $\mathrm{AF}$ & Female & $20 \mathrm{~s}$ & Adult & & & \\
\hline & $\mathrm{AF}$ & Female & $20 \mathrm{~s}$ & Adult & & & \\
\hline & $\mathrm{AF}$ & Female & $8-10$ & Adult & & & \\
\hline & $\mathrm{AF}$ & Female & $7-9$ & Adult & & & \\
\hline & $\mathrm{JM}$ & Male & $0-6$ & Calf/Juvenile & & & \\
\hline & $\mathrm{CM}^{\mathrm{a}}$ & Male & $0-3$ & Calf & & & \\
\hline & $\mathrm{CF}^{\mathrm{a}}$ & Female & $0-2$ & Calf & & & \\
\hline & $\mathrm{JF}$ & Female & $0-4$ & Calf/Juvenile & & & \\
\hline \multirow[t]{5}{*}{ B } & & & & & V & $\mathrm{C}$ & 37 \\
\hline & $\mathrm{AM}^{\mathrm{b}}$ & Male & $20-21$ & Adult & & & \\
\hline & $\mathrm{AF}^{\mathrm{b}}$ & Female & $18-19$ & Adult & & & \\
\hline & $\mathrm{JM}^{\mathrm{a}}$ & Male & $5-6$ & Juvenile & & & \\
\hline & $\mathrm{JF}^{\mathrm{a}}$ & Female & $4-5$ & Juvenile & & & \\
\hline \multirow[t]{5}{*}{$\mathrm{C}$} & & & & & E & I & 130 \\
\hline & $\mathrm{AM}$ & Male & $20 s ? ?$ & Adult & & & \\
\hline & $\mathrm{AF}$ & Female & $30 \mathrm{~s}$ & Adult & & & \\
\hline & $\mathrm{AF}$ & Female & $30 \mathrm{~s}$ & Adult & & & \\
\hline & SAM & Male & 12 & Sub-Adult & & & \\
\hline
\end{tabular}

Note. The age class definitions are as follows: Adult - sexually mature individuals with successful production of offspring. Subadult is sexually mature but has not yet successfully sired a calf. Juvenile - not sexually mature. Calf - newborn until weaned. ${ }^{a}$ Calves moved to Facility B prior to this study.

${ }^{\mathrm{b}}$ Adults that lived with the population at Facility A during the period of data collection.

\section{Study 1 - Developing a Comprehensive Catalog of Beluga Sexual and Socio-Sexual Behavior}

\section{Behavioral Catalog}

A review of a variety of sources (e.g., peer-reviewed articles, book chapters, encyclopedia articles, anecdotal reports, and personal observations) in which socio-sexual behaviors of cetaceans were described or mentioned was conducted to compile a list of possible behaviors produced during sexual or socio-sexual interactions (Table 2). 
Hill et al. 110

Table 2

Summary of Socio-Sexual/Sexual and Select Agonistic Behaviors Across Specific Cetaceans

Summary of Socio-Sexual/Sexual and Select Agonistic Behaviors Across Specific Cetaceans

\section{Behavior Definition}

\begin{tabular}{|c|c|c|}
\hline & & (population if available) \\
\hline \multicolumn{3}{|l|}{ Displays (by a male around females) } \\
\hline Rooster strut & $\begin{array}{l}\text { Head out of water and bobble up and } \\
\text { down }{ }^{1}\end{array}$ & Shark Bay bottlenose dolphins ${ }^{1}$ \\
\hline Pectoral fin slap & Hit water with pectoral fin ${ }^{1}$ & Humpback whales ${ }^{3}$ \\
\hline Varied others & Leaps, areal displays, body slaps & Shark Bay bottlenose dolphins ${ }^{1}$ \\
\hline \multicolumn{3}{|c|}{ Synchronous displays (made by $2+$ males in the presence of females) } \\
\hline Butterfly & Figure eights & Shark Bay bottlenose dolphins ${ }^{1}$ \\
\hline Varied others & & Shark Bay bottlenose dolphins ${ }^{1}$ \\
\hline Vocalizations & Sounds produced by animal & Humpback whales ${ }^{1}$ \\
\hline Bubble stream & $\begin{array}{l}\text { Trail of bubbles produced from blow } \\
\text { hole }\end{array}$ & Shark Bay bottlenose dolphins ${ }^{1}$, Humpback whales ${ }^{1}$ \\
\hline \multicolumn{3}{|c|}{ Synchronized behaviors between courtship pair } \\
\hline Mirrored pair swim & $\begin{array}{l}2 \text { animals match swim patterns } \\
\text { maintaining synchrony }\end{array}$ & Marineland bottlenose dolphin ${ }^{3}$ \\
\hline Body rubbing & $\begin{array}{l}\text { The actor moves its body along the } \\
\text { receiver's body or object }\end{array}$ & Marineland bottlenose dolphin ${ }^{3}$ \\
\hline Genital rubs & $\begin{array}{l}\text { The actor moves its genital region along } \\
\text { the receiver's body or object }\end{array}$ & Resident killer whales ${ }^{2}$ \\
\hline Genital inspections & $\begin{array}{l}\text { Animal orients at the genitalia of another } \\
\text { animal }\end{array}$ & Shark Bay bottlenose dolphins ${ }^{1}$, Resident killer whales ${ }^{2}$ \\
\hline Insertions & Fin, fluke, penis into genital or blowhole & Italy-housed bottlenose dolphin ${ }^{5}$ \\
\hline Goosing & $\begin{array}{l}\text { Rostrum positioned on genitalia with } \\
\text { contact/ insertion }\end{array}$ & $\begin{array}{l}\text { Shark Bay bottlenose dolphins }{ }^{1} \text {, Marineland bottlenose } \\
\text { dolphin }^{3}\end{array}$ \\
\hline Erections & $\begin{array}{l}\text { Penis is extended externally from the } \\
\text { genital slit }\end{array}$ & Resident killer whales ${ }^{2}$ \\
\hline \multicolumn{3}{|l|}{ Presenting } \\
\hline Horizontal & $\begin{array}{l}\text { Animal positioned parallel to water } \\
\text { surface and sometimes curved in an S- } \\
\text { formation }\end{array}$ & Marineland bottlenose dolphin ${ }^{3}$ \\
\hline Lateral (Figure 2) & $\begin{array}{l}\text { Animal positioned on its side, with pec } \\
\text { fins perpendicular to the water surface } \\
\text { and ventral side directed at second } \\
\text { animal }\end{array}$ & Humpback whales ${ }^{4}$, Marineland bottlenose dolphin ${ }^{3}$ \\
\hline Vertical (Figure 6) & $\begin{array}{l}\text { Animal positioned with head and flukes } \\
\text { perpendicular to water surface and } \\
\text { ventral side directed at second animal }\end{array}$ & Beluga whale ${ }^{6}$ \\
\hline \multicolumn{3}{|c|}{ Mounting (can be paired with intromission attempt) } \\
\hline Initiator ventral to receiver's side & Different positions in which one animal & Shark Bay bottlenose dolphins ${ }^{1}$ \\
\hline Side-to-dorsal & is swimming within $1 \mathrm{~m}$ of other animal & Shark Bay bottlenose dolphins ${ }^{1}$ \\
\hline Ventral-to-ventral & and making genital directed movements & Coast of Portugal ${ }^{7}$ bottlenose dolphins ${ }^{3,8}$ \\
\hline Spiral swimming, ventral-to-ventral & & Coast of Portugal bottlenose dolphins ${ }^{3}$ \\
\hline
\end{tabular}

Note. ${ }^{1}$ Mann et al.,(2000); ${ }^{2}$ Baird (2000); ${ }^{3}$ Connor \& Peterson (1994); ${ }^{4}$ Helweg et al. (1993); ${ }^{5}$ Tizzi, Accorsi, \& Azzali (2010);

${ }^{6}$ Horback et al. (2010); ${ }^{7}$ Tavolga \& Essapian (1957); ${ }^{8}$ dos Santos \& Lacerda (1987) 


\section{Sample and Procedure}

A focal follow protocol was used to document the behavior of beluga mothers and their calves housed at Facility A four to six times a week from June 2007-June 2009. Approximately $850 \mathrm{hrs}$ of data, evenly distributed between behavioral ethograms and video recordings, were examined. During this study, the population consisted of one adult male, six adult females, and four calf/juvenile belugas. Five of the adults were wild born; two females were born under human care.

\section{Preliminary Results}

An examination of these various sexual and socio-sexual interactions led to a more refined behavioral catalog representing socio-sexual and sexual interactions in belugas (Table 3). Figure 1a - f illustrates the sequence of behaviors incorporated into a socio-sexual interaction that ended with a pelvic thrust or intromission attempt. Figures 1e and 1f display behaviors that are more typical of aggressive interactions. The results of this study suggest that some behaviors have very distinct functions while other behaviors may have multiple functions depending on the context and the orientation of the presentation. For example, chin jerks and jaw pops were seen exclusively in agonistic interactions while the presence of an erection or a pectoral fin raised while in a lateral swim was observed only during sexual interactions. Seemingly agonistic chases immediately before a socio-sexual interaction were also observed. Two behaviors appeared to overlap across contexts: S-postures and open mouths. S-posture displays occurred with two topographies: an S-posture display with a vertical orientation held for twothree seconds during agonistic contexts (Figure 1f), while an S-posture display with a lateral or horizontal orientation held for two-three seconds during sexual contexts (Figure 1b). Open mouth threats were accompanied by head jerks, melon thrusts, and jaw pops or jaw claps during agonistic encounters and typically lasted less than a second (Figure 1e). In contrast, open mouths during socio-sexual interactions lasted one to four seconds and were not associated with other agonistic behaviors.

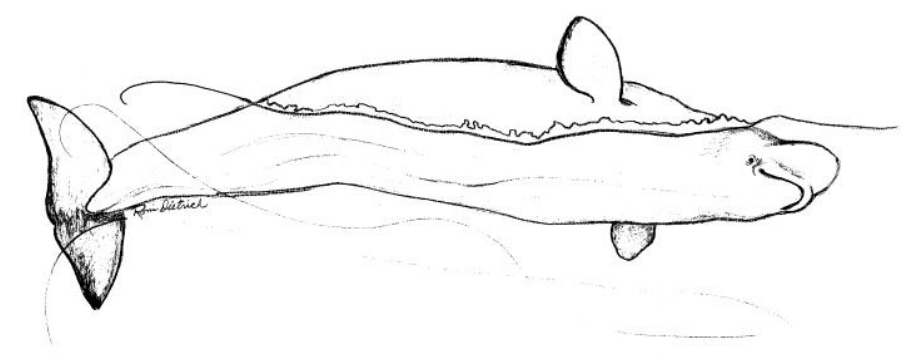

Figure 1a. Lateral swim with pectoral fin raised.

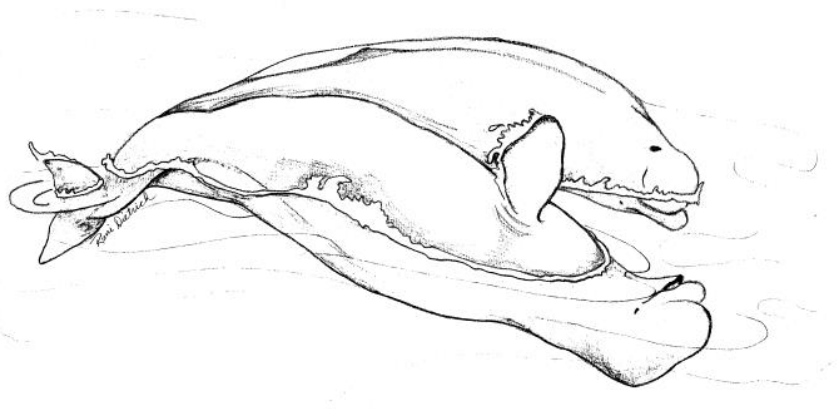

Figure 1b. Lateral or horizontal S-posture with pectoral fin raised and pelvic thrust with or without erection. 
Hill et al. 112

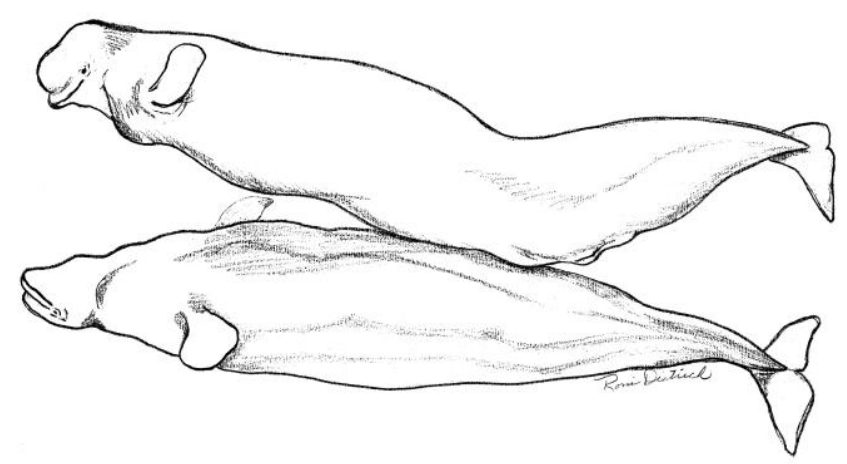

Figure 1c. Intromission attempt.

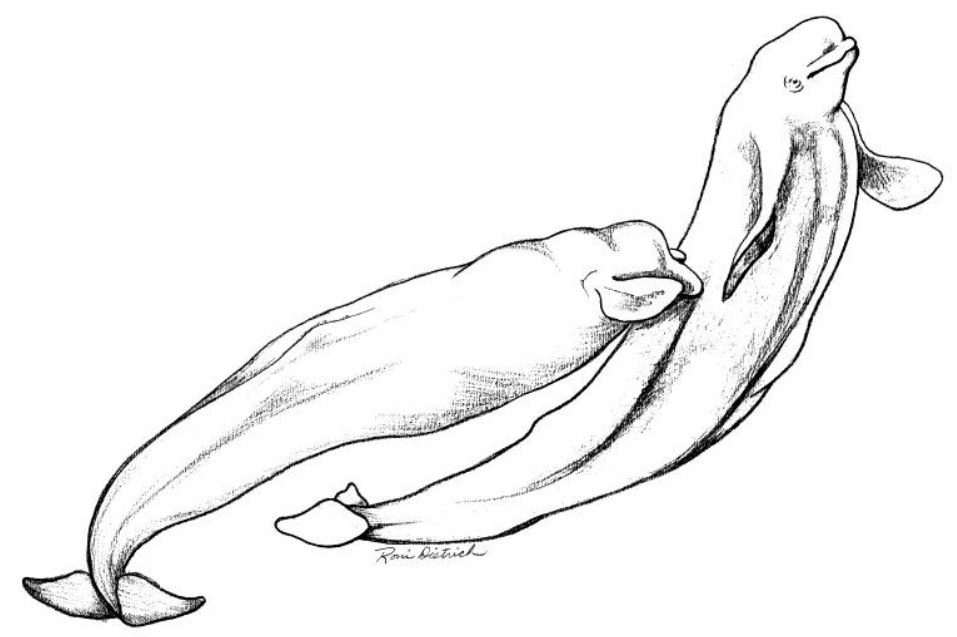

Figure 1d. Mouthing or raking. May be socio-sexual or agonistic.

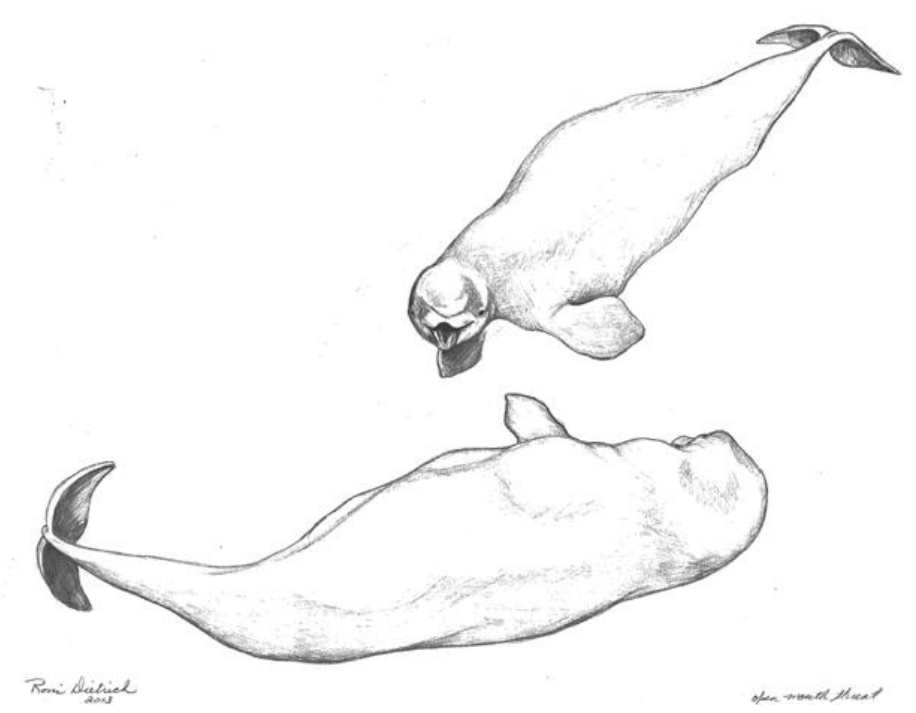

Figure 1e. Open mouth behaviors may be threatening or part of the socio-sexual sequence. 
Hill et al. 113

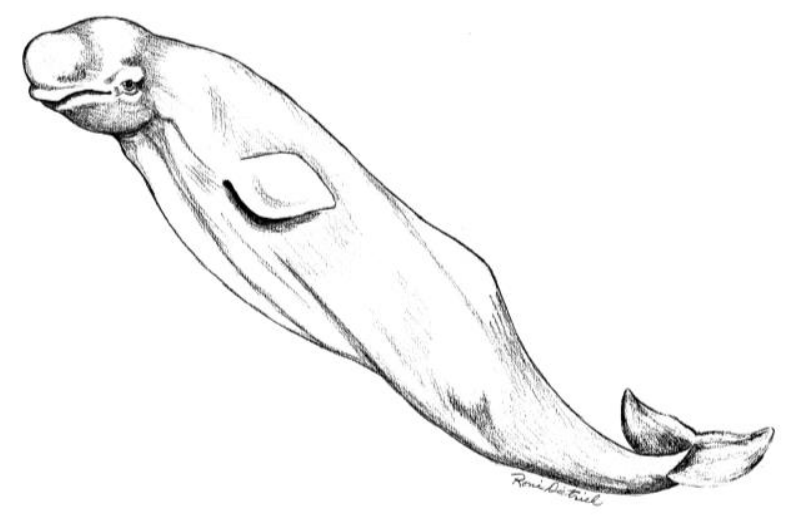

Figure 1f. Vertical S-posture used in agonistic contexts.

Table 3

Summary of Socio-Sexual/Sexual and Select Agonistic Behaviors Documented for Belugas in Human Care

Behavior

Directed gaze
Open mouth (Figure 1e)
Vocalization
Bubble stream
Pair swim
\[ \text { Synchronized } \]
Mirrored
Mouthing (Figure 1d)
Lateral swim
Pectoral fin positioned up at water
surface (Figure 1a)
Genital rubs
Erections (Figure 1c)
S-postures

Horizontal (Figure 1b)

Vertical (Figure 1f)

Pelvic thrust (Figure 1c)

Intromission

\section{Operational Definition}

The actor swings its head laterally to point the rostrum at the recipient. This behavior often involves a rapid reorientation of the actor's whole body towards the recipient.

The actor, while facing another animal, rapidly opens its mouth fully and holds it open for at least 1 second. Mutual open mouth threats do occur.

Any sound produced (whistle, chirp, clicks, squeaks, squawks

Series of small bubbles released from blow hole

When two animals swim closely together, but not necessarily in synchrony

Pair swim in which the swim trajectories are in unison

Pair swim in which two animals are faced ventral to ventral with actions that are synchronized and mirrored

The actor opens mouth and rubs it along the receiver's body, does not leave rake marks

The actor rotates body so that the pectoral fins are pointed toward the surface

The actor extends pectoral fin away from body so that the fin is perpendicular to the body

The actor moves its genital region along the receiver's body or object

Penis is extended externally from the genital slit

The actor's body is in a lateral swim position with the genitalia thrust forward and the rest of the body following in a curved position with flukes back, static hold for $2-3 \mathrm{~s}$

The actor's body is vertically positioned in the water column in the shape of an S, static hold for $2-3 \mathrm{~s}$

The actor pushes genital region toward a recipient

The act of the penis inserted into the genital slit 
The observations from this preliminary study also suggested that parts of the sexual behaviors were sequenced. For example, the belugas displayed a slow, lateral swim, pectoral fin raised (Figure 1a), with or without an erection (Figure 1c), and corresponding intromission attempt, which included a pelvic thrust and possibly a lateral S-posture (Figure 1b). Several examples were selected to illustrate the different types of socio-sexual and sexual interactions observed. From these examples, when the lateral swim events in which a pectoral fin was raised to the surface were collapsed together, the left pectoral fin was raised significantly more often than the right pectoral fin (left: $n=20$, right: $n=8$; binomial test, $p<$ $0.05)$.

\section{Study 2 - Specific Illustrations from Facility A}

\section{Sample and Procedure}

Given that the data from which the behavioral catalog was derived included focal-follow observations of young belugas and their mothers (Study 1), we selected five examples of socio-sexual interactions between different combinations of belugas to illustrate the nature of sexual and socio-sexual interactions between different partners. These examples were selected from video recordings collected at Facility A between June 2010 and May 2013 to facilitate comparisons with the two other facilities studied. Specifically, interactions between an adult male and a juvenile male (AMJM), a juvenile male and an adult female (JMAF), and two juveniles involving both males and females (JMJM and JMJF) were identified. Socio-sexual interactions between adult females have never been observed. Bouts of sociosexual interactions in these examples ranged between three and $10 \mathrm{~min}$, with a mean duration of $6.01 \mathrm{~min}$.

\section{Results}

Adult Male, Juvenile Male (AMJM). This interaction included lateral swims and short duration horizontal S-postures. In this interaction, the adult male produced six lateral swim patterns while the juvenile male produced one lateralized swim pattern. The lateralized swim patterns lasted anywhere from one to $10 \mathrm{~s}$ for the adult male and four seconds for the juvenile male. The right pectoral fin was raised during the adult male's lateral swims five of seven times and the left pectoral fin was raised two of seven encounters. The adult male was the initiator of all behaviors documented during this interaction with the juvenile male. The juvenile male responded one time with a lateral swim while raising the left pectoral fin. Following two of the lateralized swim patterns by the adult male to the juvenile male, the adult male displayed one-second agonistic vertical S-postures directed at the juvenile male.

Juvenile Male, Adult Female (JMAF). The same juvenile male from the first example was the initiator and displayed lateral swims and S-postures to an unrelated adult female. The interaction began with a left pectoral fin raised, lateral swim by the juvenile male directed toward the adult female for seven seconds. This display was followed by a series of open mouth displays by the juvenile at the adult female while he swam around the female. These open mouth displays lasted one to two seconds. Subsequent behaviors by the juvenile male included mouthing along the dorsal ridge of the female and additional open mouths. The adult female responded mainly with agonistic behaviors including open mouth displays and head jerks, although she maintained proximity to the juvenile male as he swam around her in lateral swims. This interaction lasted for one minute and six seconds.

Juvenile-Juvenile (JMJF, JMJM). In juvenile interactions, both male and female juveniles initiated socio-sexual interactions. Behaviors included lateral swims, open mouths, body/genital rubs, and horizontal S-postures, and pelvic thrusts. In the first interaction, a juvenile female ( 21 months old) initiated the event with a juvenile male ( 2 years and 10 months). The female began with a one second long lateral position and a two second, sustained open mouth. The male then responded one minute later with a three second lateral swim in which the left pectoral fin was raised. Later on within the same event, the juvenile female initiated a lateral swim with her left pectoral fin raised for two seconds. The juvenile male responded with a three second long sustained open mouth behavior coupled with a lateral swim 
lasting five seconds. The male calf also rubbed his ventral side along the female's dorsal ridge in a three second passing. For the rest of the interaction, the juvenile female displayed four lateral swims with raised pectoral fins, three left and one right, lasting one to four seconds. The male displayed one more lateral swim and two additional open mouth behaviors lasting one to four seconds as well. Interestingly, the end of this interaction included agonistic behaviors: open mouths, chin slaps, head jerks, and vertical Spostures initiated and received by both belugas.

A second juvenile-juvenile socio-sexual interaction occurred between two male belugas, both three years in age. One juvenile male initiated all behaviors between the two belugas, except for one pelvic thrust near the end of the interaction. Three lateral swims were displayed by the initiating male lasting two seconds, five seconds, and one second. Two of these lateral swims were characterized by the right pectoral fin raised.

The final example involved a $10 \mathrm{~s}$ interaction between a juvenile male (58 months) and a juvenile female (34 months). The almost five-year-old male initiated a genital rub on the almost three-year-old female for three seconds while the female swam laterally with her left pectoral fin raised for four seconds. All of these interactions suggest that socio-sexual interactions between juveniles include a variety of socio-sexual behaviors (lateral swims, open mouths, body/genital rubs, and horizontal S-postures) and sexual behaviors (pelvic thrusts) observed in other socio-sexual interactions between different classes (e.g., age and sex) of belugas.

\section{Study 3 - Socio-Sexual Behaviors from Facility B}

\section{Sample and Procedure}

A second population of four belugas was examined using the behavioral catalog developed from observations of the population at Facility A. The purpose of Study 3 was to confirm whether the behaviors cataloged at Facility A were also exhibited by belugas at a different facility and thereby conserved across the environments. The population of four belugas at Facility B included an adult male, an adult female, a juvenile male, and a juvenile female (Table 1). All belugas were unrelated and had been housed as a group at Facility B for two years. These same belugas had also been housed at Facility A during the initial study. Additionally, the juvenile males were genetically related, sharing the same sire. From June 2012-May 2013, focal follows were conducted for each juvenile beluga although all four belugas were visible in the recordings (Table 1). Out of $37 \mathrm{hrs}$ of video recordings, 147 socio-sexual interactions for a total of more than $16 \min (0.74 \%$ of total video time $)$ occurred between the four belugas (Table 4).

\section{Results}

Adult Male, Juvenile Male (AMJM, $\boldsymbol{n}=\mathbf{6 6}$ ). Interactions between the two males accounted for the majority of individual socio-sexual interactions and total time spent in socio-sexual behaviors (Table 4). As indicated by the number of behaviors observed during the different interactions, the exchanges between males were more complex than those involving females. These interactions involved an open mouth behavior almost $60 \%$ of the interactions, as compared to interactions between other pair combinations (AA, AMJF, \& JJ, Table 4). When the juvenile male initiated socio-sexual interactions with the adult female, he directed open mouth displays toward the female in 50\% of the interactions (Table 4). Although the averaged duration of individual acts of an interaction (e.g., lateral swim with presentation until an animal left) was longer between males $(M=7.9 \mathrm{~s}, S E M=0.97, n=66)$ than other combinations $(M=5.6 \mathrm{~s}, S E M=0.55, n=59)$, this difference was not statistically different, dependent $t$-test $(59)=$ $1.02, p>0.05$. Almost half of the male-to-male interactions were reciprocated by the other male (Table 4). Ten percent of AMJM interactions also showed synchrony between the two males with the recipient mirroring the initiator's behavior (e.g., initiating beluga presents ventral side to recipient while in lateral swim and the receiving beluga responds with a mirrored display). Eight percent of the male-to-male 
interactions did not have a clear initiator due to this synchronization. The three erections observed in this study occurred during mixed sex interactions (Table 4).

Adult Male, Adult Female (AMAF, $\boldsymbol{n}=\mathbf{2 2}$ ). Interactions between the two adults accounted for $15 \%$ of all interactions and $13 \%$ of total time in socio-sexual activities (Table 4). These interactions tended to be isolated events that were rarely reciprocated $(n=3)$ and only consisted of a ventral side presentation while in a lateral swim and horizontal or lateral S-postures. In one case, the male directed an open mouth toward the female. The adult male initiated $73 \%$ of these interactions (Table 4). Only one interaction between the adult male and female involved an erection. No intromission attempt was made.

Juvenile Male, Juvenile Female (JMJF, $\boldsymbol{n}=\mathbf{4 2}$ ). The two juvenile belugas interacted frequently as well, accounting for $29 \%$ of all interactions and $26 \%$ of total time engaged in socio-sexual behavior (Table 4). Seventeen percent of JMJF interactions involved an open mouth (Table 4). These interactions were reciprocated in $12 \%$ of their interactions. However, $81 \%$ of the socio-sexual interactions initiated by the juvenile male toward the juvenile female were seemingly ignored by the juvenile female, as indicated by her non-response.

Adult Female, Juvenile Female (AFJF, $\boldsymbol{n}=\mathbf{0})$. Socio-sexual interactions between the two females were not observed. Affiliative social interactions between the two females included brief pair swims that were not synchronous. Agonistic social interactions occurred occasionally with the juvenile female swimming between the adult female and the juvenile male as the adult female produced open mouth threat displays toward the male or toward the juvenile female.

Table 4

Summary of Socio-Sexual Interactions for Four Belugas at Facility B

\begin{tabular}{|c|c|c|c|c|c|}
\hline & AMAF & AMJM & AMJF & JMAF & JMJF \\
\hline Frequency & $15 \%$ & $45 \%$ & $9 \%$ & $3 \%$ & $29 \%$ \\
\hline $\mathrm{T}_{\mathrm{f}}=147$ interactions & 22 Interactions & 66 Interactions & 13 Interactions & 4 Interactions & 42 Interactions \\
\hline Time & $13 \%$ & $52 \%$ & $7 \%$ & $2 \%$ & $26 \%$ \\
\hline $\mathrm{T}_{\mathrm{t}}=16 \mathrm{~min} 36 \mathrm{~s}$ & $2 \min 7 \mathrm{~s}$ & $8 \min 40 \mathrm{~s}$ & $1 \min 6 s$ & $22 \mathrm{~s}$ & $4 \mathrm{~min} 21 \mathrm{~s}$ \\
\hline Average Duration (s) & 5.8 & 7.9 & 5.0 & 5.5 & 6.2 \\
\hline Behaviors & $\begin{array}{l}\text { Primarily only } \\
\text { ventral side } \\
\text { presentations and } \\
\text { horizontal S- } \\
\text { postures. } \\
\text { Interactions were } \\
\text { typically isolated } \\
\text { events. }\end{array}$ & $\begin{array}{l}\text { Behavior included } \\
\text { open mouths, } \\
\text { lateral swims, } \\
\text { ventral side } \\
\text { presentations, } \\
\text { horizontal S- } \\
\text { postures, and } \\
\text { genital rubs. } \\
\text { Interactions were } \\
\text { complex and } \\
\text { repeated, } \\
\text { sometimes with } \\
\text { short breaks before } \\
\text { starting again. }\end{array}$ & $\begin{array}{l}\text { Somewhat similar } \\
\text { to AMAF behavior, } \\
\text { with ventral side } \\
\text { presentations and } \\
\text { horizontal S- } \\
\text { postures, though } \\
\text { more frequent open } \\
\text { mouth behavior, } \\
\text { and one incident of } \\
\text { synchronized } \\
\text { behavior. }\end{array}$ & $\begin{array}{l}\text { Included ventral } \\
\text { side } \\
\text { presentations, } \\
\text { horizontal S- } \\
\text { postures, and } \\
\text { open mouth } \\
\text { behavior. }\end{array}$ & $\begin{array}{l}\text { Behavior included } \\
\text { open mouths, } \\
\text { lateral swims, } \\
\text { ventral side } \\
\text { presentations, and } \\
\text { horizontal S- } \\
\text { postures. } \\
\text { Sometimes } \\
\text { reciprocated and } \\
\text { one incident of } \\
\text { synchronized } \\
\text { behavior. }\end{array}$ \\
\hline Open Mouth & $5 \%$ & $59 \%$ & $23 \%$ & $50 \%$ & $17 \%$ \\
\hline Erection & One bout* & Never & One bout* & Never & Two bouts \\
\hline Initiator & $\begin{array}{c}\text { Male: } 73 \% \\
\text { Female: } 27 \%\end{array}$ & $\begin{array}{c}\text { Adult: } 41 \% \\
\text { Juvenile: } 52 \% \\
\text { Ambiguous: } 8 \%\end{array}$ & $\begin{array}{c}\text { Adult: } 69 \% \\
\text { Juvenile: } 31 \%\end{array}$ & $\begin{array}{c}\text { Adult: } 50 \% \\
\text { Juvenile: } 50 \%\end{array}$ & $\begin{array}{c}\text { Male: } 86 \% \\
\text { Female: } 12 \% \\
\text { Ambiguous: } 2 \%\end{array}$ \\
\hline
\end{tabular}

Note. Interaction Types: AA=Adult Male/Adult Female, AMJM=Adult Male/Juvenile Male, AMJF=Adult Male/Juvenile

Female, JMAF=Juvenile Male/Adult Female, JJ=Juvenile Male/Juvenile Female

*Adult and juvenile females were responding to same adult male erection display. 


\section{Study 4 - Socio-Sexual Behaviors from Facility C}

\section{Sample and Procedure}

The purpose of Study 4 was to document the socio-sexual behaviors exhibited by belugas located at a third facility. Facility $\mathrm{C}$ housed two adult females (A and B), one adult male, and a sub-adult male (Table 1). All belugas were unrelated and unfamiliar to any of the other belugas previously studied. Data collection began with the adult male's introduction to the social group in October 2011 and continued through August 2014. The last five months of data were collected with the adult male, one adult female, and the sub-adult male after the death of the other adult female in March 2014. Although the behavioral categories and definitions were consistent with the data collection from Study 2 and Study 3, a oneminute instantaneous scan sampling method was used to collect data two to six hours a week for an estimated total of $130 \mathrm{hrs}$ of observations (Table 1). To facilitate comparisons between the facilities, the sample points were converted to percentages to create an activity budget for each animal and to examine the frequency of partners. We expected similar socio-sexual behaviors to be exhibited by this population of belugas if the behaviors were conserved across the species. The data for Study 4 were organized by beluga rather than interaction types to accommodate the sampling method and the nature of the resulting interactions.

\section{Results}

Adult Male (AM) ${ }^{1}$. When interacting socially, the two males spent $92 \%$ of these interactions with each other. In contrast, the adult male spent $8 \%$ of his time interacting with the two adult females. Of these social interactions, $69 \%$ were with the sub-adult male while $25 \%$ were with Female A and $2 \%$ with Female B. The adult male spent $6 \%$ of his total time engaged in pair swims with $60 \%$ of the pair swims involving the sub-adult male, $37 \%$ with Female A, and 3\% with Female B. Sexual contact in which the genital region of one animal was touched only occurred $0.67 \%$ of the total time observed for the adult male. Of this small percent, 97\% $(n=33)$ of the sexual contact behaviors occurred with the sub-adult male. There was only one instance (out of 34) of sexual contact between the adult male and Female A. Open mouth behaviors by the adult male were also observed, with $72 \%$ of the open mouths directed toward the sub-adult male. The adult male also exhibited open mouth behaviors towards Female A and B, $10 \%$ and $5 \%$ respectively.

Sub-adult Male (SM) ${ }^{1}$. The sub-adult male spent $10 \%$ of all observations combined interacting socially with other whales. Of this time, he spent $60 \%$ with the adult male, $34 \%$ with Female A, and $2 \%$ with Female B. The remaining $4 \%$ was spent in a group swim with both the adult male and Female A. The sub-adult male spent $7 \%$ of all observations combined pair swimming with others. Of these events, $77 \%$ of the pair swims were with the adult male, $20 \%$ with female A, and $3 \%$ with female B. Socio-sexual behaviors were very rare, constituting less than $1 \%(n=40)$ of his total activity budget. However, $100 \%$ of all his instances of sexual contact behaviors occurred with the adult male. When open mouths were examined, the sub-adult male directed $8 \%$ of his open mouth behaviors toward the adult male, $6 \%$ towards Female A, and less than $1 \%$ towards Female B.

Adult Female A (AFSM/AFAF). Although many of the sub-adult male's agonistic behaviors were directed toward Female A, she did not reciprocate with any aggressive behaviors towards the subadult male and her most common response was to flee. However, these interactions constituted less than $1 \%$ of her total interactions with him. Finally, extremely few female-to-female social interactions occurred overall, with only two pair swims recorded between the females for the entire study.

\footnotetext{
${ }^{1}$ Percentages representing number of interactions with specific animals do not always add to $100 \%$ due to non-visible sample points.
} 


\section{Discussion}

The current understanding of cetacean mating systems, their related socio-sexual or sexual and agonistic behaviors, and the role of innate or learned mechanisms is sparse. Our limited knowledge is restricted primarily to specific species (e.g., bottlenose dolphins and humpback whales), with much of this information scattered across a variety of sources and anecdotal reports (e.g., DiPaola et al., 2007; Glabicky et al., 2010; Helweg et al., 1993; Horback, Friedman, \& Johnson, 2010; Mann, Connor, Tyack, \& Whitehead, 2000; Sauer, 1963). Despite concerns of artificial environments, some topics are particularly conducive to study with controlled populations, such as agonistic behavior or socio-sexual behavior (reviewed by Samuels \& Tyack, 2000). With access to three different beluga populations in human care, the purpose of this study was two-fold: (1) to compile a comprehensive behavioral catalog of their socio-sexual and shared agonistic behaviors and (2) to examine the nature of these behaviors in three beluga populations in human care.

Consistent with the findings of previous research (Helweg et al., 1993; Horback et al., 2010), the agonistic interactions and sexual interactions observed were not mutually exclusive as many of the observations included the exchange of both agonistic and sexual behaviors. The topography of behaviors found in the interactions differed subtly yet consistently by their timing, three-dimensional orientation, ancillary behaviors, and sequence. For example, S-postures, previously reported for belugas (Horback et al., 2010) and gray whales (Helweg et al., 1993), were displayed in two orientations that were context specific: during agonistic interactions, S-postures were presented in a vertical orientation while during sexual or socio-sexual interactions S-postures were presented in a lateral orientation. These S-postures differed in their head and peduncle positions (Figure 1c and 1f) from S-postures displayed by bottlenose dolphin males (head and peduncle are both arched up) during courtship interactions with females (see Figure on p. 153, Connor \& Peterson, 1994). Future studies should measure the leading body part in lateral and vertical S-postures as our observations suggested that the agonistic vertical S-posture may lead with the head, while the sexual lateral S-posture may lead with the genitals. Although the sample from which the behavioral catalog was derived from mother-calf pair focal follows, sexual or socio-sexual interactions between adult females and the adult male were less frequent than sexual or socio-sexual interactions between calves, juveniles, sub-adults, and the adult male. The sub-adult male performed the most agonistic behaviors when examining the case study at Facility $\mathrm{C}$. This result may have been due to the difficulty in interpreting the context as strictly aggressive since the sub-adult may be more curious and playful with his adult social partners in general, possibly due the social grouping and the lack of any similar-aged peers.

\section{Beluga Socio-Sexual Repertoire}

The development of a comprehensive behavioral catalog of socio-sexual behavior in belugas was validated on three different groups of belugas (Table 3). Although not all behaviors were represented in every socio-sexual or sexual interaction, many of the behaviors appear to have sequenced elements (Figures 1a-d). For example, socio-sexual presentations involved (a) a lateral swim with the ventral side presented to the receiving animal, that was (b) paired with an upright presentation of the surface-facing pectoral fin by the initiating animal, and sometimes followed by (c) a horizontal/lateral S-posture that may be held for one to three seconds, that typically (d) transformed into a pelvic thrust of the genitals towards the receiving animal (with or without contact, Figure 1). Preliminary evidence suggests that this sequence may be lateralized with a left pectoral fin positioned up toward the water surface, possibly facilitating the initiator's left-eye processing of the receiver's reciprocal social response (e.g., Karenina et al., 2010; Karenina, Giljov, Glazov, \& Malashichev, 2013).

Other socio-sexual interactions involved open mouth displays between the initiator and receiver or mouthing along the dorsal ridge and peduncle region. Additional behaviors observed, but not necessarily at all three facilities, included directed gazes during which the initiating animal oriented at the receiving animal from across the pool, long trails of fine to small bubbles released from the blowhole, and 
genital rubs along other animals or objects. Vocalizations also occurred but were not evaluated. Vocalizations need to be addressed further as identified in an earlier ethogram developed by the training staff at Vancouver Aquarium, Vancouver, British Columbia, Canada (DiPaola et al., 2007). Erections primarily occurred between males or between juvenile males and females. Although many of the initial observations were derived from data collected from mother-calf beluga pairs (i.e., Facility A), all three facilities had mature females that cycled or could have cycled during the data collection periods. Unfortunately, no intromissions between adult males and adult females were observed directly. However, several calves were conceived and birthed at Facility A during the data collection period, suggesting that copulations had occurred. Twenty-four hour observations and hormonal monitoring of sexually receptive adults are suggested for future studies to better understand the behavior that precedes copulation attempts.

While intromissions were not observed, similar to the study conducted by Glabicky and colleagues (2010), one behavioral pattern emerged that should be investigated further: close proximity (less than a body length apart) pair swims between belugas that may be synchronized or mirrored. Unlike many delphinids (dolphins: Connor, Smolker, \& Bejder, 2006; Fellner, Bauer, Stamper, Losch, \& Dahood, 2013; Hill \& Lackups, 2010; Mann \& Smuts, 1999; Perelberg \& Schuster, 2008; killer whales: Ray, Carlson, Carlson, Carlson, \& Upson, 1986; Ljungblad \& Moore, 1983), adult belugas in human care rarely swim together (H. Hill, personal observations). Thus, observations of pair swims between adult belugas or between two males suggest that these swims might be purposeful and functional (e.g., increased opportunity for mating or bond formation such as in some bottlenose dolphins, Connor, Read, et al., 2000; Dudzinski et al., 2009).

Agonistic behaviors that were observed included head jerks, open mouth threats, melon thrusts, charges, displacements, vertical S-postures, and jaw pops. Several of these behaviors were observed during interactions that ultimately became socio-sexual in nature, including the presence of an erection and/or a pelvic thrust. For example, vertical S-postures have been previously reported to be used as a visual threat by belugas (Horback et al., 2010). Vertical S-postures were exhibited by belugas at all three facilities in a variety of contexts identified as agonistic (e.g., receiving individual escaped, avoided, was displaced, or responded in kind with an appropriate display). Another ambiguous behavior was an open mouth, which was also observed in multiple contexts and may show subtle differences in topography or ancillary behaviors, depending on the context (e.g., Connor, Read, et al., 2000; Mann \& Smuts, 1999). Additional research is necessary to better understand the subtleties and functions of both behaviors.

\section{Socio-Sexual Behavioral Trends: Facility, Sex, Age}

The collective results from the three facilities suggest two important conclusions. First, beluga socio-sexual behaviors appear to be conserved across at least these three facilities. The animals at each facility exhibited similar types of socio-sexual behaviors. In particular, the adult males directed similar behaviors to adult females in all facilities (e.g., pair swimming with lateral presentation of the genital area to the female). Likewise, the male-to-male display of socio-sexual interactions produced many consistent patterns (e.g., ventral-to-ventral pair swimming with horizontal/lateral S-postures and pelvic thrusting and sometimes open mouths and bubble streams). The male-to-male interactions observed at Facility B and C were unique in their frequency, duration, and topography as compared to other types of interactions (e.g., JJ, AA). The degree of synchronization of male-to-male interactions and the lack of female-to-female interactions were especially intriguing. It is unclear if this synchronization is specific to mostly male behavior, juvenile behavior, or is ultimately dependent upon the receiver. Although synchronized maleto-male interactions were not frequently observed at Facility A, the lack of these interactions may have been due to the age of the younger male belugas (less than four years).

Second, the age, reproductive status, and sex of the animals involved in a socio-sexual interaction affected the pattern of socio-sexual behavior. The specific examples from the different facilities suggest that while the majority of the elements of the socio-sexual repertoire are present in adult-adult sociosexual interactions, some behaviors did not occur as often or as long as when those behaviors are displayed in male-to-male or juvenile-initiated interactions. Finally, when mixed-sex, socio-sexual 
interactions were considered, the males tended to initiate these interactions although juvenile females initiated more socio-sexual interactions with juvenile males than with adult males or adult females with males. In contrast, the initiator of the socio-sexual interaction seemed to be shared more consistently when the interaction occurred between same sex but different age class belugas.

\section{Innate Mechanisms and Learned Behavior}

Despite the similarities in the socio-sexual and select agonistic behaviors, it is possible that the males may use some behaviors more or less frequently and with varying degrees of success while the females may display differing preferences. Evidence for this possibility is provided in the evolution and preferences of humpback whales during the breeding season (Clapham, 2000). Long-term studies in which the development of the sexual and socio-sexual repertoire is documented in multiple, controlled populations would provide insight into the question of innate mechanism versus learned behaviors (i.e., Freeberg, 2000). These studies would facilitate our understanding of the differences and purposes of socio-sexual behavior and overlapping agonistic behaviors. In particular, we should focus on questions, such as (1) if the behaviors are learned, how are they learned (e.g., trial and error, modeling), (2) what models are appropriate, (3) what is the role of age, and (4) is a reproductive advantage conferred? Pursuing these questions with populations in human care may help extant populations that are currently having difficulty recovering in their natural habitats (e.g., Cook Inlet, Jefferson et al., 2012). As Samuels and Tyack (2000) summarized, social behaviors are easier to observe in controlled environments than in natural habitats. If some of the socio-sexual behaviors are learned socially then it is possible that certain social groupings may be necessary to facilitate reproductive success. For example, the reciprocal interactions between a juvenile male beluga and an adult male beluga may be critical to the long-term reproductive success of the younger belugas. If this hypothesized condition is supported by research with populations in human care, then management of in situ populations may be implicated (e.g., adult male belugas should not be culled). Additional investigation of male-to-male socio-sexual interactions and other social interactions is needed to determine if these interactions are consistent across contexts, including different facilities and contexts (e.g., in human care versus free-ranging).

\section{Summary}

Animals in controlled settings that produce spontaneous behavior that is similar to their freeranging conspecifics evidence that the controlled environment is supportive of their welfare. Thus, studies that explore aspects of spontaneous behavior that can be also be evaluated with free-ranging populations, such as the current study, are critical to assessing the welfare of beluga populations in human care and in their natural habitat. Using previously established ethograms and anecdotal reports, a comprehensive behavioral catalog was developed and then tested using three different populations of belugas. These controlled populations varied in sample size, age, reproductive status, sex, and length of study.

The results of the study at Facility A in which many of the observations were derived from observations of calves with their mothers and companions suggested that some socio-sexual behaviors emerged early and were practiced with similar-aged peers. Additional observations on this population when the oldest calf had reached a juvenile status indicated that male-to-male socio-sexual and sexual interactions increased in frequency and complexity. The frequency of socio-sexual interactions between the juvenile male and some of the adult females were also observed. Similar findings were observed in two follow-up studies at two independent facilities that housed two juveniles and two adults of mixed sex and three adults of mixed sex with one sub-adult male, respectively. Some differences in the frequency of several behaviors emerged and additional research is needed to understand the factors influencing these trends.

As a follow-up to this study, we propose that additional research on the long-term reproductive outcomes of the success of the developing juvenile male and female belugas be evaluated using multiple measures, including hormonal, physiological, and behavioral measures. We also suggest that similar 
systematic studies should be performed for other cetaceans that differ in their social structures to understand the influence of social groupings on the nature and frequency of socio-sexual behaviors on bond formation and future reproductive success.

\section{Acknowledgements}

We would like to thank the management, training, animal care, and veterinary staffs of SeaWorld San Antonio, Georgia Aquarium, and Mystic Aquarium for their commitment to this longitudinal project. We also appreciate the data collection and data analysis efforts of all the research assistants, volunteers, and staff at all three facilities. Many thanks to Roni Dietrich for her accurate illustrations of the beluga behaviors represented in this study. Finally, our appreciation to several reviewers for their comments on earlier drafts of this paper. In particular, Chris Bellows, Dr. Judy St. Leger, Dr. Tracey Romano, and Dr. Kathleen Dudzinski provided valuable feedback on earlier drafts of this paper. This paper represents contribution - TC\# 2014-02-T for SeaWorld.

\section{References}

Baird, R. W. (2000). The killer whale. In J. Mann, R. C. Connor, P. L. Tyack, \& H. Whitehead (Eds.), Cetacean societies: Field studies of dolphins and whales (pp. 127-153). Chicago: The University of Chicago.

Bel'kovich, V. M. (1960). Some biological observations on beluga from the air. Zoological Zh Akademy Nauk, 39 , 1414-1421.

Baker, C. S., \& Herman, L. M. (1984). Aggressive behavior between humpback whales (Megapteranovaeangliae) wintering in Hawaiian waters. Canadian Journal of Zoology, 62, 1922--937.

Best, R. C., \& da Silva, V. M. (1984). Preliminary analysis of reproductive parameters of the boutu, Inia geoffrensis, and the tucuxi, Sotalia fluviatilis, in the Amazon River system. Reports of the International Whaling Commission, Special, 6, 361-369.

Brodie, P. F. (1971). A reconsideration of aspects of growth, reproduction, and behavior of the white whale (Delphinapterus leucas), with reference to the Cumberland Sound, Baffin Island, population. Journal of the Fisheries Board of Canada, 28, 1309-1318.

Campbell, C. J. (2007). Primate sexuality and reproduction. In C. J. Campbell, A. Fuentes, K. C. MacKinnon, M. Panger, \& S. K. Bearder (Eds.), Primates in perspective (pp. 423-437). Oxford: Oxford University Press.

Clapham, P. J. (2000). The humpback whale. In J. Mann, R. C. Connor, P. L. Tyack, \& H. Whitehead (Eds.), Cetacean societies, field studies of dolphins and whales (pp. 173-196). Chicago: The University of Chicago.

Colbeck, G. J., Duchesne, P., Postma, L. D., Lesage, V., Hammill, M. O., Turgeon, J. (2013). Groups of related belugas (Delphinapterus leucas) travel together during their seasonal migrations in and around Hudson Bay. Proceedings of the Royal Society, Biology, 280, 2552-2561. doi:10.1098/rspb.2012.2552

Connor, R. C., \& Peterson, D. M. (1994). The lives of whales and dolphins. New York: Henry Holt and Company.

Connor, R. C., Read, A. J., \& Wrangham, R. (2000). Male reproductive strategies and social bonds. In J. Mann, R. C. Connor, P. L. Tyack, \& H. Whitehead (Eds.), Cetacean societies: Field studies of dolphins and whales, (pp. 247-269). Chicago: The University of Chicago.

Connor, R. C., Smolker, R., \& Bejder, L. (2006). Synchrony, social behaviour and alliance affiliation in Indian Ocean bottlenose dolphins, Tursiops aduncus. Animal Behaviour, 72, 1371-1378.

Connor, R. C., Wells, R. S., Mann, J., \& Read, A. J. (2000). The bottlenose dolphin: Social relationships in a fission-fusion society. In J. Mann, R. C. Connor, P. L. Tyack, \& H. Whitehead (Eds.), Cetacean societies: Field studies of dolphins and whales (pp. 91-126). Chicago: The University of Chicago.

Craig, A. S., Herman, L. M., Gabriele, C. M., \& Pack, A. A. (2003). Migratory timing of humpback whales (Megaptera novaeangliae) in the central North Pacific varies with age, sex and reproductive status. Behaviour, 140, 981-1001.

DiPaola, S., Akai, C., \& Kraus, B. (2007). Experiencing belugas: Developing an action selection-based aquarium interactive. Journal of Adaptive Behavior, Special Issue on Action Selection, 15, 99-113. doi: $10.1177 / 1059712306076251$ 
Dudzinski, K. M., Gregg, J. D., Ribic, C. A., \& Kuczaj, S. A. (2009). A comparison of pectoral fin contact between two different wild dolphin populations. Behavioural Processes, 80, 182-190. doi: 10.1016/j.beproc.2008.11.011

Everitt, R. D., \& Krogman, B. D. (1979). Sexual behavior of bowhead whales observed off the north coast of Alaska. Arctic, 32, 277-280.

Fellner, W., Bauer, G. B., Stamper, S. A., Losch, B. A., \& Dahood, A. (2013). The development of synchronous movement by bottlenose dolphins (Tursiops truncatus). Marine Mammal Science, 29, E203-E225.

Freeberg, T. M. (2000). Culture and courtship in vertebrates: A review of social learning and transmission of courtship systems and mating patterns. Behavioural Processes, 51, 177-192.

Furuichi, T., Connor, R., \& Hashimoto, C. (2014). Non-conceptive conceptive sexual interactions in monkeys, apes, and dolphins. In J. Yamagiwa \& L. Karczmaski (Eds.), Primates and cetaceans: Field research and conservation of complex mammalian societies (pp. 385-408). Japan: Springer.

Glabicky, N., DuBrava, A., \& Noonan, M. (2010). Social-sexual behavior seasonality in captive beluga whales (Delphinapterus leucas). Polar Biology, 33, 1145-1147.

Heide-Jørgensen M. P., \& Teilmann, J. (1994). Growth, reproduction, age structure and feeding habits of white whales (Delphinapterus leucas) in West Greenland waters. Bioscience 39, 195-212.

Helweg, D. A., Bauer, G. B., \& Herman, L. M. (1993). Observations of an S-shaped posture in humpback whales (Megaptera novaeangliae). Aquatic Mammals, 18, 74-78.

Hill, H. (2009). The behavioral development of two beluga calves during the first year of life. International Journal of Comparative Psychology, 22, 234-253.

Hill, H., Artz, S., \& Lopez, M. (2014). Sex, love, or war? A representation of 20 years of research on the social interactions of animals. International Journal of Comparative Psychology, 27, 50-68.

Hill, H., Campbell, C., Dalton, L., \& Osborn, S. (2013). The first year of behavioral development and maternal care of beluga (Delphinapterus leucas) calves in human care. Zoo Biology, 32, 565-570.

Hill, H., \& Lackups, M. (2010). Journal publication trends regarding cetaceans found in both wild and captive environments: What do we study and where do we publish? International Journal of Comparative Psychology, 23, 414-534.

Hill, H., \& Ramirez, D. (2014). Adults play but not like their young: The frequency and types of play by belugas (Delphinapterus leucas) in human care. Animal Behavior and Cognition, 1, 166-185. doi: 10.12966/abc.05.07.2014

Horback, K. M., Friedman, W. R., \& Johnson, C. M. (2010). The occurrence and context of s-posture display by captive belugas (Delphinapterus leucas). International Journal of Comparative Psychology, 23, 689-700.

Jefferson, T. A., Karkzmarski, L., Laidre, K., O’Corry-Crowe, G., Reeves, R., Rojas-Bracho, L., ...Zhou, K. (2012). Delphinapterus leucas. The IUCN Red List of Threatened Species. Version 2014.2. www.iucnredlist.org. Downloaded on 01 October 2014.

Karenina, K., Giljov, A., Baranov, V., Osipova, L., Krasnova, V., \& Malashichev, Y. (2010). Visual laterality of calf-mother interactions in wild whales. PloS one, 5(11), e13787.

Karenina, K., Giljov, A., Glazov, D., \& Malashichev, Y. (2013). Social laterality in wild beluga whale infants: Comparisons between locations, escort conditions, and ages. Behavioral Ecology and Sociobiology, 67, 1195-1204.

Kleinenberg, S. E., Yablokov, A. V., Bel'kovich, V. M., \& Tarasevich, M. N. (1969). Belukha. Opyt monograficheskogo issledovaniya vida (Beluga. Targeted Investigation of the Species). Moscow, Russia: Nauka.

Krasnova, V. V., Bel'kovich, V. M., \& Chernetsky, A. D. (2006). Mother-infant spatial relations in wild beluga (Delphinapterus leucas) during postnatal development under natural conditions. Biology Bulletin, 33, 5358.

Krasnova, V. V., Bel'kovich, V. M., \& Chernetsky A. D. (2009). Formation of behavior in the White Sea beluga calf, Delphinapterus leucas, during early postnatal ontogenesis. Russian Journal of Marine Biology, 35, 53-59.

Kraus, S. D., \& Hatch, J. J. (2001). Mating strategies in the North Atlantic right whale (Eubalaena glacialis). Journal of Cetacean Research and Management (Special Issue), 2, 237-244.

Ljungblad, D. K., \& Moore, S. E. (1983). Killer whales (Orcinus orca) chasing gray whales (Eschrichtius robustus) in the northern Bering Sea. Arctic, 36, 361-364.

Lorenz, K. Z. (1958). The evolution of behavior. Scientific American, 199, 67-78.

Lusseau, D. (2006). Why do dolphins jump? Interpreting the behavioural repertoire of bottlenose dolphins (Tursiops sp.) in Doubtful Sound, New Zealand. Behavioural Processes, 73, 257-265. 
Mann, J., \& Smuts, B. (1999). Behavioral development in wild bottlenose dolphin newborns (Tursiops sp.). Behaviour, 136, 529-566.

Mann, J., Connor, R. C., Tyack, P. L., \& Whitehead, H. (2000). Cetacean societies: Field studies of dolphins and whales. Chicago: University of Chicago Press.

Martin, A. R., Da Silva, V. M. F., \& Rothery, P. (2008). Object carrying as socio-sexual display in an aquatic mammal. Biology Letters, 4, 243-245.

National Marine Fisheries Service. (2008). Conservation plan for the Cook Inlet beluga whale (Delphinapterus leucas). National Marine Fisheries Service, Juneau, Alaska.

O’Corry-Crowe, G. M., Suydam, R. S., Rosenberg, A., Frost, K. J. \& Dizon, A. E. (1997). Phylogeography, population structure and dispersal patterns of the beluga whale (Delphinapterus leucas) in the western Nearctic revealed by mitochondrial DNA. Molecular Ecology, 6, 955-970.

Perelberg, A., \& Schuster, R. (2008). Coordinated breathing in bottlenose dolphins (Tursiops truncatus) as cooperation: Integrating proximate and ultimate explanations. Journal of Comparative Psychology, 122, 109-120.

Perelberg, A., Veit, F., van der Woude, S. E., Donio, S., \& Shashar, N. (2010). Studying dolphin behavior in a seminatural marine enclosure: Couldn't we do it all in the wild? International Journal of Comparative Psychology, 23, 625-643.

Ray, R. D., Carlson, M. L., Carlson, M. A., Carlson, T. M., \& Upson, J. D. (1986). Behavioral and respiratory synchronization quantified in a pair of captive killer whales. In B. C. Kirkevold \& J. S. Lockard (Eds.), Behavioral biology of killer whales (pp. 135-147). New York: Alan R. Liss, Inc.

Samuels, A., \& Tyack, P. L. (2000). Flukeprints: A history of studying cetacean societies. In J. Mann, R. C. Connor, P. L. Tyack, \& H. Whitehead (Eds.), Cetacean societies: Field studies of dolphins and whales (pp. 9-44). Chicago: The University of Chicago.

Sauer, E. F. (1963). Courtship and copulation of the gray whale in the Bering Sea at St. Lawrence Island, Alaska. Psychological Research, 27, 157-174.

Sergeant, D. E. (1973). Biology of the white whales (Delphinapterus leucas) in western Hudson Bay. Journal of Fisheries and Research Board of Canada, 30, 1065-1090.

Smith, T. G., Hammill, M. O., \& Martin, A. R. (1994). Herd composition and behaviour of white whales (Delphinapterus leucas) in two Canadian arctic estuaries. In E. E. Born, R. Dietz, \& R. R. Reeves (Eds.), Studies of white whales (Delphinapterus leucas) and Narwhals (Monodon monoceros) in Greenland and adjacent waters, Vol. 39 (pp. 175-184). Copenhagen, Denmark: Commission for Scientific Research in Greenland.

Tinbergen, N. (1952). The curious behavior of the stickleback. Scientific American, 87, 22-26.

Tizzi, R., Accorsi, P. A., \& Azzali, M. (2010). Non-invasive multidisciplinary approach to the study of reproduction and calf development in bottlenose dolphin (Tursiops truncatus): The Rimini Delfinario Experience. International Journal of Comparative Psychology, 23, 734-776.

Tyack, P. L. (2000). Functional aspects of cetacean communication. In J. Mann, R. C. Connor, P. L. Tyack, \& H. Whitehead (Eds.), Cetacean Societies: Field studies of dolphins and whales (pp. 270-307). Chicago: The University of Chicago.

Tyack, P., \& Whitehead, H. (1983). Male competition in large groups of wintering humpback whales. Behaviour, $83,132-154$. 